
they will protect as far as possible the interests of private families and
family practitioners.

SUgGestions.

(x) The public vaccinator before entering a house should ascertain whether thele is in fact, as reported to him, an unvaccinated child in the house.

(2) In the event of his being informed that there is not an unvaccinated child in the house; or if there is, that arrangements have been made for its private vaccination, the public vaccinator should then at once retire (3) Should the public vaccinator be informed that the child is too ill to duty to require a certificate of unfitness to be supplied; that is the duty of duty to require a certificat

(4) It is not the duty of the public vaccinator, nor is it compatible with the dignity of his profession, to endeavour to persuade the parents to le him perform the vacin

(5) The public vaccinator as such should not proceed to examine any child as to its state of health unless he has been requested to vaccinat it, and unless he is bona fide under the impression that the to vaccinat be vaocinated. In any other case his duty is to abstain from all interbe vaocinated. In any

(6) Any reference as to the superiority of his methods or his vaccine made with the view of being allowed to vaccinate, would be mos unworthy, and could only be exceeded in this respect by any attempt to decry the methods or the vaccine employed by other practitioners.

(7) If he is required to vaccinate a child belonging to a family who are the patients of another practitioner, he is in honour and in self respect bound to avoid any act or word which might tend to prejudice the professional interests of the family medical attendant, or which could be regarded as an attempt to induce the family to employ him as their family doctor.

(8) The public vaccinator is not authorised to call, for the purpose of vaccinating a child, until after the expiration of the 24 hours' notice which he is required to give.

\section{Gratuitous Vaccination.}

A.- We cannot suggest any means by which a medical man other than the public vaccinator of a district can be prevented from vaccinating gratuitously children of the poorer classes.

\section{INSUSCEPTIBILITY TO VACCINATION}

F.W. J. writes: The certificate forms for "insusceptibility to vaccination" issued by the registrar of births state that vaccination must have operation three times before certifying that the child is insusceptible to vaccination

** The Vaccination Act, 1867 , Section $\mathbf{x x}$, unrepealed, reads thus : "If any such public vaccinator or medical practitioner shall find that a child whom he has three times unsuccessfully vaccinated is insusceptible of successful vaccination, or that a child has already had the small-pox, he shall deliver to the parent or other person as aforesaid a certificate to that effect." It is therefore evident that, in order to sign the certificate, it is necessary by the Act that three unsuccessful attempts should have been made. It should be added that in the $188_{7}$ Report of the Medical Officer of the Local Government Board, Dr. Cory reports having performed 38,000 primary vaccinations, and only once to have failed twice in an attempt to vaccinate.

\section{ONE OR Two MaRK Vaccination.}

G. writes: One of the "public vaccinators" recently called at a house; the mother declined his services on account of the four marks. He then offered to do it "privately" for less than the Government fee, and only put one or two marks on. This offer was declined as the mother cinate me to do it. The same gentleman some time since called to vaccinate a baby, found it suffering from pneumonia, criticised my treatno longer required. no longer required. How can I insist or even suggest that I should put on more inarks than the parents wish? The Act is wrong. It is scientious objection" will exempt them entirely.

R.S.A.-The matter is one upon which the Local Government Board alone could give any decision.

\section{Fees in Police-court Cases.}

R.W.-The fee payable to a medical man for attendance at police court and giving evidence in vaccination cases ran only be governed by the same rules as obtain in regard to any other police-court cases. There is no provision in the Vaccination Act or Order requiring him to appear or fxing any fee. It is usual for a medical witness to receive half a guinea for police-court attendance, and if his evidence is required in several cases the fee would properly be charged in each case.

\section{A REPORT OF THE POLLUTION OF THE RIVERS LEE AND STORT.}

By Herbert Arthur Kynsey, M.R.C.S., L.R.C.P., D.P.H.Lond.

THE River Lee rises some three miles north-west of the town of Luton in Bedfordshire, and flowing through Hatiield Hertford, Ware, Broxbourne, Waltham, Ponders End, Edmonton, Tottenham, Hackney, Bow, and Stratford, enters the
Thames by Blackwall, close to the Isle of Dogs. It windo somewhat sluggishly through a flat country, between very low banks, and is navigable from the Thames as far as Hertford. The country is mainly chalk and gravel, with some clay. A special officer, Major Lamrock Flower, was appointed in 1871 to the charge of the watershed, and much has been done of late years under him to prevent sewage entering the river by irrigation, and the establishment of sewage farms, but a great deal still remains to be accomplished by preventing the accumulation of refuse on the banks. Although constant complaints are made by the Lee Conservancy through their officials to the landowners on whose grounds this nuisance exists; little notice has been taken of them. Moreover, the carriage of manure is especially sanctioned by Act of Parliament.

The River Stort rises near the small village of Elsenham in Essex, and flowing through Bishop Stortford, Sawbridgeworth, Harlow, Burnt Mill, and Roydon, joins the Lee at Fields Weir, about 2 miles from Broxbourne. The Stort is a sluggish stream, with a very winding course, passing at first through chalk, and thence over a tertiary formation covered more or less with drift. The navigation of this river is not under the Lee Conservancy. It flows straight into the Lee, and contributes a great portion of the water for the East London Waterworks Company, but in common with all tributary streams is under the Lee Conservancy Board for protection of water purposes.

According to Mr. Symons, F.R.S., the mean rainfall of the Lee Valley above the water companies' intakes is 26.5 inches.

\section{The Traffic in Manure.}

A large part of the traffic on these rivers consists of barges laden with manure, which is used on the lands adjacent to their banks. This manure, so called, is composed of the refuse of ashpits, mud, dung, and the general filth of London, including oyster, lobster, and other shells, fish, bones, scrap iron of all sorts, old bedding, carpets, bottles, boots, and rags, paper, sacking, straw, vegetable débris, and dead animals.

The manure, having been brought up the river, is "dumped" in large masses, varying from 10 to 100 tons, on the banks, there to wait until it is either ploughed into the land, sifted into fine ash, or burnt. It is highly offensive, in the first place, and is rendered even more so by the putrefactive changes which it undergoes whilst awaiting removal.

Apart from what actually falls into the river in transferring the cargo from the barges, a large amount is necessarily washed in by the rainfall, owing to the position of these manure heaps, which in some cases are placed almost on the water edge; but this is contrary to the by-laws of the Conservancy Board, and the prevention of this cause of pollution is a source of everlasting trouble.

The following by-law is in force on the Lee :

Manure, gas lime, or other materials are not permitted to be landed or unloaded on single planks, but sufficient means by a platform or otherwise must be provided to prevent anything falling into the river.

This by-law, according to my own personal observations, is a dead letter.

When gas lime or manure has been unloaded on the towpath side, naturally the towpath must be left for traffic, the barges being towed by horses, but when unloaded on the other side of the river it is dumped down anyhow, close to the edge of the bank. On my pointing this fact out to an ancient resident in the neighbourhood, he explained the whole situation thus: "Well, yer see, guv'nor, a bargee aint a goin' to walk io feet when he need only walk $\mathrm{r}$."

The owners of the land adjoining the river are alleged to be responsible for this state of affairs. As they do not look after the bargees the latter do as they please, and take as little trouble as possible, which is after the nature of the bargee.

As regards the unloading of barges, I have seen single planks only used, on which the manure is carried in wheelbarrows, some part of the load invariably falling into the river, the banks themselves being in a filthy condition, the river polluted, and the stench sickening.

On the Stort there is a by-law that no gas lime or manure shall be placed with in 14 feet of the river, an improvement on the by-law of the Lee theory, but in practice never carried 
out. As to the unloading, the bargemen do as they please, the only care taken, I was informed, being that of not overloading the barrows.

\section{The Condition of the Lee.}

To enter more into detail, I will start from Ponders End Lock, which is some 200 yards above Kidd's Weir, the intake of the East London Waterworks Company.

The river here is very dirty and after a heavy rainfall, which as I before remarked washes some of the refuse into the river, may be absolutely filthy. I saw tin cans, bottles, straw, decayed vegetables, and dirty paper in abundance; I do not say that it is always as bad as this, but this part of the river struck me as being certainly the dirtiest.

For almost the whole length of the bank from Ponders End Lock to close upon Enfield Lock, the western bank is covered with these manure heaps close to the water's edge; much of it falls into the river and is caught amongst the weeds at the side.

I inspected two out of three wharves where manure is collected. On one the manure was only some 4 feet away from the bank of a dock adjoining the Lee. Some hundreds of tons were lying here, the banks were littered with filth, and the smell was horrible, On another wharf the refuse was placed just 10 feet from the water, but could easily be washed in by rain, the stench was also fearful, and caused great annoyance in the neighbourhood.

Above Broxbourne I saw some barges unloading, no adequate precautions being taken to prevent their contents falling into the river, and that it did fall in was evident. Above Dobbs Weir there were large collections of manure and gas lime close to the water's edge.

Below Ware Lock the water was inky-looking and very dirty ; this might be accounted for by the fact that there were hundreds of tons of sifted ash, that is, sifted manure heaps on the banks, no attempt being made to comply with the regulations as to distance. Complaints were made about the smells in the neighbourhood. From here to Hertford there was no nuisance of any kind that I could discover.

Since the Lee Conservancy appointed a water bailiff about a year ago, whose duty it is specially to look after the manure traffic, things have, I hear, greatly improved, but it is impossible for him to be everywhere at once, and unless his reoommendations are backed up by rigorous prosecutions against all offenders against the by-laws, affairs will go on in the same seeming happy-go-lucky fashion, as they appear to do now.

With regard to the Stort, in one place large heaps of gas lime and manure formed a shelving bank right into the river, and in many other places masses of gas lime were thrown on to the bank, and portions could be seen half in and half out of the water.

The minimum allowance of ro and 14 feet for the Lee and Stort respectively is far too small, 20 to 25 would be barely sufficient.

This would involve a little more trouble to the bargemen, but the gain to the public would be very great. Some further means should be taken to rectify the present unsatisfactory method of unloading barges, which occurs in so many instances.

At some wharves platforms are used 3 feet broad and 12 feet long, but where these are not carried on barges, a canvas screen could be stretched from the barge to the bank, underneath the planks forming the gangway, which would catch anything that tended to fall into the river, and so prevent a very real and constant source of pollution. This is now being done to the manifest improvement of the river.

The question which is naturally forced upon us is this: Ought a navigable river to be a source of town water supply?

\section{LITERARY NOTES.}

With the July issue of the Quarterly Medical Journal Mr. Simeon Snell's connection with that periodical as editor, as the lawyers say, ceased and determined. Mr. Snell has been editor for the seven years the Quarterly Medical Journal has been in existence, and both he and the "promoters" of that publication are to be congratulated on the success of his labours. The Quarterly Medical Journal has by sheer merit won for itself an honourable place in the medical journalism of this country.

We are pleased to see that the Saturday Review, which under its former editorial régime was given over to Eddyism and the evil spirit of antiscience generally, is now once more on the side of the angels. Its issue of July 8th contains an excellent article on Preventive Inoculation, in which, after describing with intelligent sympathy Mr. Haffkine's work in India, it says: "We may be thankful that within the limits of the Empire there is at least one great country where scientific investigation of first-rate importance to suffering humanity is being conducted under the protection and encouragement of the Government, and unhampered by the inhumane restrictions invented by ignorant humanitarians."

Mr. Chamberlain has lately reminded $M$. Yves Guyot and the world at large that les beaux esprits se rencontrent. Now it is the good fortune of Dr. E. Berdoe to afford an interesting illustration of that piece of proverbial philosophy. A body was found in a reservoir in Lancashire the other day, and Dr. Boyce promptly gave an alarmed public the comforting assurance that this particular form of organic matter would do no harm. Wereupon Dr. Berdoe was moved to write to the Westminster Gazette as follows :-

Your note on the Prescot reservoirs and the body in the water reminds me to ask a question on a matter on which I have often had my doubts. We occasionally hear of brewers' men falling into a vat of boiling beer or the stuft which is in process of becoming beer. What is done with the liquid in such cases? My reason for asking this is the fact that it some times happens that the corpse is not discovered till the beer has been all sold. In one such case I remember the customers demanded that their porter should be "the same as the last, as there was such a good body $n$ it.

This personal experience will probably make Dr. Berdoe grateful to us for directing his attention to that recondite work, Marryat's Pacha of Many Tales, where in the Story of the Greek Slave he will find a curious anticipation of the taste in drink of the connoisseurs whom he remembers. The slave murdered an Ethiopian and concealed the body in a wine cask. The wine was greatly relished by the customers, and the ingenious Greek, after pretending to taste it, was fain to agree with them (as he conscientiously could) that it had more body than the rest. Thus does history repeat itself.

Nothing, says Dr. E. H. Bradford in a recent number of the Boston Medical and Surgical Journal, is a better measure of the work of a profession than its literature. American medical literature was for a long period thoroughly provincial, and till recently American textbooks were chiefly translations or American issues of foreign books, sometimes with annotations by the American editors. But the output of native literature has been steadily increasing for some time. The catalogue of the Harvard Medical School for the year $1875-76$ gives a list of books recommended to students which includes 44 foreign books to 13 American. In the list for 1898.99 there are 85 American to $7 \mathrm{I}$ foreign textbooks. But the growth has been greater than would appear from these lists. At the beginning of the Revolutionary War there were only I book, 3 reprints and 20 pamphlets by American authors. To-day there are 7,000 books and reprints and a large number of pamphlets. There are 300 books and pamphlets written by American authors annually, and 5,000 journal articles. In 1879-1880, 10,334 books and journal articles were written in the United States, while 7,476 were written in England in the same period. The Americans are probably the greatest consumers of medical literature, and in medical libraries are foremost. The development of medical journalism has been very remarkable.

The Medical Review (St. Louis) gives some amusing illustrations of the strange changes suffered by names in the wanderings of paragraphs through different journals. Some years ago Dr. Prince Morrow wrote an article on drug dermatoses. This was abstracted in Germany, and subsequently in Hungary It reappeared in American journals credited to Dr. P. A. Moronn, a distinguished Hungarian dermatologist. In 1892 an article was written by Dr. Kiernan, of Chicago, on suicide. Within a year it returned from Japan credited to an eminent Japanese alienist, Dr. Kurnau, of Tokio, Japan, who, by a remarkable coincidence, quoted extensively from Chicago statistics. Some years ago we cited some equally curious instances of the denationalisation of authors' names in their journalistic metem- 